\title{
Late-onset, treatment-resistant anxiety and depression
}

Andrea Carr, MD, Megan Ines, DO, and Jenna Taglienti, MD

\section{How would you handle this case?}

Answer the challenge questions at MDedge.com/ psychiatry and see how your colleagues responded

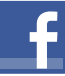

Discuss this article at www.facebook.com/ MDedgePsychiatry

\section{CASE Anxious and can't sleep}

Mr. A, age 41, presents to his primary care physician (PCP) with anxiety and insomnia. He describes having generalized anxiety with initial and middle insomnia, and says he is sleeping an average of 2 hours per night. He denies any other psychiatric symptoms. Mr. A has no significant psychiatric or medical history.

Mr. A is initiated on zolpidem tartrate, $12.5 \mathrm{mg}$ every night at bedtime, and paroxetine, $20 \mathrm{mg}$ every night at bedtime, for anxiety and insomnia, but these medications result in little to no improvement.

During a 4-month period, he is treated with trials of alprazolam, $0.5 \mathrm{mg}$ every 8 hours as needed; diazepam $5 \mathrm{mg}$ twice a day as needed; diphenhydramine, $50 \mathrm{mg}$ at bedtime; and eszopiclone, $3 \mathrm{mg}$ at bedtime. Despite these treatments, he experiences increased anxiety and insomnia, and develops depressive symptoms, including depressed mood, poor concentration, general malaise, extreme fatigue, a 15-pound unintentional weight loss, erectile dysfunction, and decreased libido. Mr. A denies having suicidal or homicidal ideations. Additionally, he typically goes to the gym approximately 3 times per week, and has noticed that the amount of weight he is able to lift has decreased, which is distressing. Previously, he had been able to lift 300 pounds, but now he can only lift 200 pounds.
What should be the next step in Mr. A's treatment?
a) start an antipsychotic
b) start an atypical antidepressant
c) order bloodwork and imaging
d) admit him to an inpatient psychiatric unit
e) refer him for electroconvulsive therapy (ECT)

\section{The authors' observations}

Insomnia, anxiety, and depression are common chief complaints in medical settings. However, some psychiatric presentations may have an underlying medical etiology.

DSM-5 requires that medical conditions be ruled out in order for a patient to meet criteria for a psychiatric diagnosis. ${ }^{1}$ Medical differential diagnoses for patients with psychiatric symptoms can include autoimmune, drug/toxin, metabolic, infectious, neoplastic, neurologic, and nutritional etiologies (Table $1,{ }^{2}$ page 42). To rule out the possibility of an underlying medical etiology, general screening

Dr. Carr is a Staff Psychiatrist, Department of Psychiatry, Mount Sinai South Nassau, Baldwin, New York. Dr. Ines is a PGY-3 Psychiatry Resident, Department of Psychiatry, Mather Hospital, Port Jefferson, New York. Dr. Taglienti is the Residency Program Director, Department of Psychiatry, Mather Hospital, Port Jefferson, New York.

\section{Disclosures}

The authors report no financial relationships with any companies whose products are mentioned in this article, or with manufacturers of competing products.

doi: $10.12788 /$ cp. 0160 
guidelines include complete blood count, complete metabolic panel, urinalysis, and urine drug screen with alcohol. Human immunodeficiency virus testing and thyroid hormone testing are also commonly ordered. ${ }^{3}$ Further laboratory testing and imaging is typically not warranted in the absence of historical or physical findings because they are not advocated as costeffective, so health care professionals must use their clinical judgment to determine appropriate further evaluation. The onset of anxiety most commonly occurs in late adolescence early and adulthood, but Mr. A experienced his first symptoms of anxiety at age $41 .^{2} \mathrm{Mr}$. A's age, lack of psychiatric or family history of mental illness, acute onset of symptoms, and failure of symptoms to abate with standard psychiatric treatments warrant a more extensive workup.

\section{EVALUATION Imaging reveals an important finding}

Because Mr. A's symptoms do not improve with standard psychiatric treatments, his PCP orders standard laboratory bloodwork to investigate a possible medical etiology; however, his results are all within normal range.

After the PCP's niece is coincidentally diagnosed with a pituitary macroadenoma, the PCP orders brain imaging for Mr. A. Results of an MRI show that Mr. A has a $1.6-\mathrm{cm}$ macroadenoma of the pituitary. He is referred to an endocrinologist, who orders additional laboratory tests that show an elevated 24-hour free urine cortisol level of $73 \mu \mathrm{g} / 24 \mathrm{~h}$ (normal range: 3.5 to $45 \mu \mathrm{g} / 24 \mathrm{~h}$ ), suggesting that $\mathrm{Mr}$. A's anxiety may be due to Cushing's disease or that his anxiety caused falsely elevated urinary cortisol levels. Four weeks later, bloodwork is repeated and shows an abnormal dexamethasone suppression test, and 2 more elevated 24-hour free urine cortisol levels of $76 \mu \mathrm{g} / 24 \mathrm{~h}$ and $150 \mu \mathrm{g} / 24 \mathrm{~h}$. A repeat MRI shows a 1.8-cm, mostly cystic sellar mass, indicating the need for surgical intervention.
Although the tumor is large and shows optic nerve compression, Mr. A does not complain of headaches or changes in vision.

Two months later, Mr. A undergoes a transsphenoidal tumor resection of the pituitary adenoma, and biopsy results confirm an adrenocorticotropic hormone (ACTH)secreting pituitary macroadenoma, which is consistent with Cushing's disease. Following surgery, steroid treatment with dexamethasone is discontinued due to a persistently elevated Am cortisol level. After the surgery, Mr. A takes a leave of absence from work.

\section{Which of the following psychiatric symptoms can be a presenting symptom of Cushing's disease?}
a) depression
b) anxiety
c) mania
d) psychosis
e) all of the above
f) none of the above

\section{The authors' observations}

Chronic excess glucocorticoid production is the underlying pathophysiology of Cushing's disease, which is most commonly caused by an ACTH-producing adenoma. ${ }^{4,5}$ When these hormones become dysregulated, the result can be over- or underproduction of cortisol, which can lead to physical and psychiatric manifestations. ${ }^{6}$

Cushing's disease most commonly manifests with the physical symptoms of centripetal fat deposition, abdominal striae, facial plethora, muscle atrophy, bone density loss, immunosuppression, and cardiovascular complications. ${ }^{5}$

Hypercortisolism can precipitate anxiety ( $12 \%$ to $79 \%$ ), mood disorders ( $50 \%$ to $70 \%$ ), and (less commonly) psychotic disorders; however, in a clinical setting, if a patient presented with one of these as a chief complaint, they would likely first be treated psychiatrically rather than worked up medically for a rare medical condition. . $7-13^{-13}$

\section{Clinical Point \\ In Cushing's disease, overproduction of cortisol can lead to physical and psychiatric symptoms}




\section{Clinical Point}

\section{Hypercortisolism can precipitate anxiety, mood disorders, and psychotic disorders}

\section{Table 1}

\section{Differential diagnosis of medical conditions with psychiatric manifestations}

\begin{tabular}{|c|c|}
\hline Category & Examples \\
\hline Autoimmune conditions & Systemic lupus erythematosus, NMDA receptor encephalitis \\
\hline $\begin{array}{l}\text { Medications, illicit } \\
\text { substances, or toxins }\end{array}$ & $\begin{array}{l}\text { Environmental toxins (organophosphates, heavy metals, carbon monoxide), } \\
\text { substance-related intoxication/withdrawal or delirium or substance-induced } \\
\text { neurocognitive disorder, adverse effects of medication }\end{array}$ \\
\hline $\begin{array}{l}\text { Endocrine/metabolic } \\
\text { conditions }\end{array}$ & $\begin{array}{l}\text { Cushing's disease/syndrome, diabetes mellitus, hyperglycemia/ } \\
\text { hypoglycemia, SIADH, parathyroid disease, hypercalcemia/hypocalcemia, } \\
\text { pheochromocytoma, pregnancy, Wilson's disease, hepatic encephalopathy }\end{array}$ \\
\hline Infectious diseases & $\begin{array}{l}\text { HIV, systemic viral/bacterial infections, neurosyphilis, herpes simplex } \\
\text { encephalitis, meningitis, infectious mononucleosis, tuberculosis, Lyme } \\
\text { disease, prion disease }\end{array}$ \\
\hline Neoplastic conditions & CNS tumors, paraneoplastic syndrome, endocrine tumors \\
\hline Neurologic conditions & $\begin{array}{l}\text { Alzheimer's disease, Lewy Body dementia, Parkinson's disease, } \\
\text { Huntington's disease, anoxic brain injury, stroke, frontotemporal dementia, } \\
\text { head trauma, migraine headaches, normal pressure hydrocephalus, seizure } \\
\text { disorders, sleep disorders }\end{array}$ \\
\hline Nutritional conditions & $\begin{array}{l}\text { Vitamin B12 deficiency, folate deficiency, nicotinic acid deficiency, thiamine } \\
\text { deficiency, trace mineral deficiency (zinc, magnesium) }\end{array}$ \\
\hline
\end{tabular}

Mr. A's initial bloodwork was unremarkable, but cortisol levels were not obtained at that time because testing for cortisol levels to rule out an underlying medical condition is not routine in patients with depression and anxiety. In Mr. A's case, a neuroendocrine workup was only ordered once his PCP's niece coincidentally was diagnosed with a pituitary adenoma.

For Mr. A, Cushing's disease presented as a psychiatric disorder with anxiety and insomnia that were resistant to numerous psychiatric medications during an 8-month period. If Mr. A's PCP had not ordered a brain MRI, he may have continued to receive ineffective psychiatric treatment for some time. Many of Mr. A's physical symptoms were consistent with Cushing's disease and mental illness, including erectile dysfunction, fatigue, and muscle weakness; however, his 15-pound weight loss pointed more toward psychiatric illness and further disguised his underlying medical diagnosis, because sudden weight gain is commonly seen in Cushing's disease (Table 2, ${ }^{4,5,7,9}$ page 43).

\section{TREATMENT Persistent psychiatric symptoms, then finally relief}

Four weeks after surgery, Mr. A's psychiatric symptoms gradually intensify, which prompts him to see a psychiatrist. A mental status examination (MSE) shows that he is well-nourished, with normal activity, appropriate behavior, and coherent thought process, but depressed mood and flat affect. He denies suicidal or homicidal ideation. He reports that despite being advised to have realistic expectations, he had high hopes that the surgery would lead to remission of all his symptoms, and expresses disappointment that he does not feel "back to normal."

Six days later, Mr. A's wife takes him to the hospital. His MSE shows that he has a tense appearance, fidgety activity, depressed and anxious mood, restricted affect, circumstantial thought process, and paranoid 
delusions that his wife was plotting against him. He says he still is experiencing insomnia. $\mathrm{He}$ also discloses having suicidal ideations with a plan and intent to overdose on medication, as well as homicidal ideations about killing his wife and children. Mr. A provides reasons for why he would want to hurt his family, and does not appear to be bothered by these thoughts.

Mr. A is admitted to the inpatient psychiatric unit and is prescribed quetiapine, 100 mg every night at bedtime. During the next 2 days, quetiapine is titrated to $300 \mathrm{mg}$ every night at bedtime. On hospital Day 3, Mr. A says he is feeling worse than the previous days. $\mathrm{He}$ is still having vague suicidal thoughts and feels agitated, guilty, and depressed. To treat these persistent symptoms, quetiapine is further increased to $400 \mathrm{mg}$ every night at bedtime, and he is initiated on bupropion $\mathrm{XL}$, $150 \mathrm{mg}$, to treat persistent symptoms.

After 1 week of hospitalization, the treatment team meets with Mr. A and his wife, who has been supportive throughout her husband's hospitalization. During the meeting, they both agree that Mr. A has experienced some improvement because he is no longer having suicidal or homicidal thoughts, but he is still feeling depressed and frustrated by his continued insomnia. Following the meeting, Mr. A's quetiapine is further increased to $450 \mathrm{mg}$ every night at bedtime to address continued insomnia, and bupropion $\mathrm{XL}$ is increased to $300 \mathrm{mg} / \mathrm{d}$ to address continued depressive symptoms. During the next few days, his affective symptoms improve; however, his initial insomnia continues, and quetiapine is further increased to $500 \mathrm{mg}$ every night at bedtime.

On hospital Day 20, Mr. A is discharged back to his outpatient psychiatrist and receives quetiapine, $500 \mathrm{mg}$ every night at bedtime, and bupropion XL, $300 \mathrm{mg} / \mathrm{d}$. Although Mr. A's depression and anxiety continue to be well controlled, his insomnia persists. Sleep hygiene is addressed, and alprazolam, $0.5 \mathrm{mg}$ every night at bedtime, is added to his regimen, which proves to be effective.
Table 2

\section{Clinical features of Cushing's disease}

\begin{tabular}{|l|c|}
\hline Medical features & Frequency \\
\hline Obesity, weight gain, thin skin & $80 \%$ \\
\hline Moon facies, hypertension & $75 \%$ \\
\hline Purple striae, hirsutism & $65 \%$ \\
\hline $\begin{array}{l}\text { Abnormal glucose tolerance, } \\
\text { impotence }\end{array}$ & $55 \%$ \\
\hline $\begin{array}{l}\text { Proximal muscle weakness, } \\
\text { truncal obesity }\end{array}$ & $50 \%$ \\
\hline $\begin{array}{l}\text { Acne, bruising, mental } \\
\text { changes }\end{array}$ & $45 \%$ \\
\hline Osteoporosis & $40 \%$ \\
\hline Diabetes mellitus & $15 \%$ \\
\hline Psychiatric features & Frequency \\
\hline Depression & $50 \%$ to $80 \%$ \\
\hline Anxiety & $66 \%$ to $79 \%$ \\
\hline Panic disorder & $3 \%$ to $37 \%$ \\
\hline Mania or hypomania & $3 \%$ to $30 \%$ \\
\hline Psychosis & $8 \%$ \\
\hline Source: References $4,5,7,9$ & \\
\hline
\end{tabular}

\section{OUTCOME A slow remission}

After a year of treatment, Mr. A is slowly tapered off of all medications. Two years later, he is in complete remission of all psychiatric symptoms and no longer requires any psychotropic medications.

\section{The authors' observations}

Treatment for hypercortisolism in patients with psychiatric symptoms triggered by glucocorticoid imbalance has typically resulted in a decrease in the severity of their psychiatric symptoms. ${ }^{9,11}$ A prospective longitudinal study examining 33 patients found that correction of hypercortisolism in patients with Cushing's syndrome often led to resolution of their psychiatric symptoms, with $87.9 \%$ of patients back to baseline within 1 year. ${ }^{14}$ However, to our knowledge, few reports have described the management of

\section{Clinical Point \\ The severity of psychiatric manifestations of Cushing's disease may correlate with cortisol levels}




\section{Clinical Point}

Serum cortisol levels can be used as a screening tool for underlying medical causes in a patient with anxiety and depression

\section{Related Resources}

- Roberts LW, Hales RE, Yudofsky SC, ed. The American Psychiatric Association Publishing Textbook of Psychiatry. 7th ed. American Psychiatric Association Publishing; 2019.

- Rotham J. Cushing's syndrome: a tale of frequent misdiagnosis. National Center for Health Research. 2020. www.center4 research.org/cushings-syndrome-frequent-misdiagnosis/

- Middleman D. Psychiatric issues of Cushing's patients: coping with Cushing's. Cushing's Support and Research Foundation. www.csrf.net/coping-with-cushings/psychiatricissues-of-cushings-patients/

Drug Brand Names

Alprazolam • Xanax

Bupropion - Wellbutrin

Dexamethasone • Decadron

Diazepam • Valium

Eszopiclone $\cdot$ Lunesta

Paroxetine $\cdot$ Paxil

Quetiapine $\cdot$ Seroquel

Zolpidem tartrate • Ambien CR

patients whose symptoms are resistant to treatment of hypercortisolism.

In our case, after transsphenoidal resection of an adenoma, $\mathrm{Mr}$. A became suicidal and paranoid, and his anxiety and insomnia also persisted. A possible explanation for the worsening of Mr. A's symptoms after surgery could be the slow recovery of the hypothalamic-pituitary-adrenal (HPA) axis and therefore a temporary deficiency in glucocorticoid, which caused an increase in catecholamines, leading to an increase in stress. ${ }^{14}$ This concept of a "slow recovery" is supported by the fact that Mr. A was successfully weaned off all medication after 1 year of treatment, and achieved complete remission of psychiatric symptoms for $>2$ years. Furthermore, the severity of Mr. A's symptoms appeared to correlate with his 24-hour urine cortisol and AM cortisol levels, which is also supported by the findings of Starkman et al. ${ }^{15}$ Mr. A's psychiatric symptoms were most severe when his AM cortisol levels peaked after his surgical resection, and his symptoms improved as his cortisol levels returned to normal. In the interim, while his psychiatric symptoms were exacerbated by the persistence of elevated cortisol levels, Mr. A was admitted psychiatrically and treated with psychotropic medications. Once his cortisol levels normalized and his psychiatric symptoms were well controlled with quetiapine, alprazolam, and bupropion for 1 year, he was titrated off all medications.

Future research should evaluate the utility of screening all patients with treatment-resistant anxiety and/or insomnia for hypercortisolism. Even without other clues to endocrinopathies, serum cortisol levels can be used as a screening tool for diagnosing underlying medical causes in patients with anxiety and depression. ${ }^{2}$ A greater understanding of the relationship between medical and psychiatric manifestations will allow clinicians to better care for patients. Further research is needed to elucidate the quantitative relationship between cortisol levels and anxiety to evaluate severity, guide treatment planning, and follow treatment response for patients with anxiety. It may be useful to determine the threshold between elevated cortisol levels due to anxiety vs elevated cortisol due to an underlying medical pathology such as Cushing's disease. Additionally, little research has been conducted to compare how psychiatric symptoms respond to pituitary macroadenoma resection alone, pharmaceutical intervention alone, or a

\section{Bottom Line}

Consider testing cortisol levels in patients with treatment-resistant anxiety and insomnia, because cortisol plays a role in Cushing's disease and anxiety. The severity of psychiatric manifestations of Cushing's disease may correlate with cortisol levels. Treatment should focus on symptomatic management and underlying etiology. 
combination of these approaches. It would be beneficial to evaluate these treatment strategies to elucidate the most effective method to reduce psychiatric symptoms in patients with hypercortisolism, and perhaps to reduce the incidence of post-resection worsening of psychiatric symptoms.

This case was challenging because Mr. A did not initially respond to psychiatric intervention, his psychiatric symptoms worsened after transsphenoidal resection of the pituitary adenoma, and his symptoms were alleviated only after psychiatric medications were re-initiated following surgery. This case highlights the importance of considering an underlying medically diagnosable and treatable cause of psychiatric illness, and illustrates the complex ongoing management that may be necessary to help a patient with this condition achieve their baseline. Further, Mr. A's case shows that the absence of response to standard psychiatric therapies should warrant earlier laboratory and/or imaging evaluation prior to or in conjunction with psychiatric referral. Additionally, testing for cortisol levels is not typically done for a patient with treatment-resistant anxiety, and this case highlights the importance of considering hypercortisolism in such circumstances.

\section{References}

1. Diagnostic and statistical manual of mental disorders, 5 th ed. American Psychiatric Association; 2013.

2. Sadock BJ, Sadock VA, Ruiz P, et al. Neural sciences. In: Sadock BJ, Sadock VA, Ruiz P, et al. Kaplan and Sadock's synopsis of psychiatry: behavioral sciences/clinical psychiatry. 11th ed. Wolters Kluwer; 2015.

3. Anfinson TJ, Kathol RG. Screening laboratory evaluation in psychiatric patients: a review. Gen Hosp Psychiatry. 1992;14(4):248-257.

4. Fehm HL, Voigt KH. Pathophysiology of Cushing's disease. Pathobiol Annu. 1979;9:225-255.

5. Fujii Y, Mizoguchi Y, Masuoka J, et al. Cushing's syndrome and psychosis: a case report and literature review. Prim Care Companion CNS Disord. 2018;20(5):18.

6. Raff H, Sharma ST, Nieman LK. Physiological basis for the etiology, diagnosis, and treatment of adrenal disorders: Cushing's syndrome, adrenal insufficiency, and congenital adrenal hyperplasia. Compr Physiol. 2011;4(2):739-769.

7. Santos A, Resimini E, Pascual JC, et al. Psychiatric symptoms in patients with Cushing's syndrome: prevalence diagnosis, and management. Drugs. 2017;77(8):829-842.

8. Arnaldi G, Angeli A, Atkinson B, et al. Diagnosis and complications of Cushing's syndrome: a consensus statement. J Clin Endocrinol Metab. 2003;88(12):5593-5602.

9. Sonino N, Fava GA. Psychosomatic aspects of Cushing's disease. Psychother Psychosom. 1998;67(3):140-146.

10. Loosen PT, Chambliss B, DeBold CR, et al. Psychiatric phenomenology in Cushing's disease. Pharmacopsychiatry. 1992;25(4):192-198

11. Kelly WF, Kelly MJ, Faragher B. A prospective study of psychiatric and psychological aspects of Cushing's syndrome. Clin Endocrinol. 1996;45(6):715-720.

12. Katho RG, Delahunt JW, Hannah L. Transition from bipolar affective disorder to intermittent Cushing's syndrome: case report. J Clin Psychiatry. 1985;46(5):194-196.

13. Hirsh D, Orr G, Kantarovich V, et al. Cushing's syndrome presenting as a schizophrenia-like psychotic state. Isr J Psychiatry Relat Sci. 2000;37(1):46-50.

14. Dorn LD, Burgess ES, Friedman TC, et al. The longitudinal course of psychopathology in Cushing's syndrome after correction of hypercortisolism. J Clin Endocrinol Metab. 1997;82(3):912-919.

15. Starkman MN, Schteingart DE, Schork MA. Cushing's syndrome after treatment: changes in cortisol and ACTH levels, and amelioration of the depressive syndrome Psychiatry Res. 1986;19(3):177-178.

\section{Clinical Point \\ The absence of \\ response to standard \\ psychiatric therapies should warrant earlier laboratory and/or imaging evaluation}

